\title{
Percepción sobre la construcción de competencias académicas y profesionales en Psicólogos

\section{Jesús de la Fuente Arias ${ }^{1}$, Fernando Justicia Justicia ${ }^{2}$, Pedro Félix Casanova ${ }^{3}$, María Victoria Trianes ${ }^{4}$}

Dpto. de Psicología Evolutiva y de la Educación

$$
\begin{aligned}
& { }^{1} \text { Universidad de Almería } \\
& { }^{2} \text { Universidad de Granada } \\
& { }^{3} \text { Universidad de Jaén } \\
& { }^{4} \text { Universidad de Málaga }
\end{aligned}
$$

\section{España}

jfuente@ual.es 


\section{Participantes en el Proyecto:}

UAL: Grupo de Investigación HUM-746

Dr. Jesús de la Fuente Arias. Dpto. Psicología Evolutiva y de la Educación (dir.)

Dra. Sánchez López, Pilar. Dpto. Psicología Evolutiva y de la Educación.

Dr. Soriano Ferrer, Manuel. Dpto. Psicología Evolutiva y de la Educación.

UAL: Grupo de Investigación HUM- 498

Dr. Martínez Vicente, Jose Manuel.Dpto. Psicología Evolutiva y de la Educación.

UGR: Grupo de Investigación HUM-232

Dr. Justicia, Justicia, Fernando. Dpto. Psicología Evolutiva y de la Educación (coord.).

Dr. Cano García, Francisco. Dpto. Psicología Evolutiva y de la Educación.

Dra. Pichardo Martínez, Mari Carmen. Dpto. Psicología Evolutiva y de la Educación.

UJA: Grupo de Investigación HUM-469

Dr. Casanova Arias, Pedro Felix. Dpto. Psicología. (coord.).

Dra. De la Torre Cruz, Manuel Jesús. Dpto. Psicología.

Dra. Cerezo Rusillo, M. Teresa. Dpto. Psicología.

Dra. Carpio Fernández, M. de la Villa. Dpto. Psicología.

UMA: Grupo de Investigación HUM-378

Dra. Trianes Torres, M. Victoria. Dpto. Psicología Evolutiva y de la Educación (coord.).

Dra. Muñoz Sánchez, Ángeles. Dpto. Psicología Evolutiva y de la Educación.

Dr. Fernandez Baena, Francisco. Dpto. Psicología Evolutiva y de la Educación.

INFORMÁTICO:

D. Trujillo Capel, Tomás M. Almería.

COLABORAN:

Colegio Oficial de Psicólogos de Andalucía Oriental

Delegaciones Provinciales. Junta de Andalucía. 


\section{Resumen}

Introducción. La evaluación de las competencias requeridas para el ejercicio de la profesión tiene una gran actualidad. Su importancia reside en las mejoras que se pueden efectuar en los procesos de formación inicial y permanente. En este trabajo resumimos algunos resultados obtenidos en una investigación reciente sobre esta problemática.

Método. Participaron un total de 76 sujetos, de diferente tipología, con diferente grado de titulación y que habían finalizado en diferentes momentos la carrera, con diferentes puestos actuales profesionales y nivel de experiencia profesional. Todos cumplimentaron una versión on-line de la Escala para la Evaluación de la Formación recibida por los profesionales, versión. 1.00 (De la Fuente, 2003). Efectuamos análisis descriptivos y de varianza con los datos obtenidos.

Resultados. Las competencias académico-profesionales propuestas se construyen en los dos ámbitos formativos, aunque existe un desequilibrio entre ámbitos, no siempre adecuadamente coordinados. En general, los sujetos opinan que en el contexto profesional-aplicado es donde se construyen una mayor cantidad de competencias. La mayoría del conocimiento factual (saber) se construye en el ámbito de la formación universitaria, mientras que la construcción del conocimiento procedimental (saber hacer) se produce en el ámbito aplicado.

Discusión. Consideramos que la línea de trabajo es provechosa, para evaluar la calidad de la formación recibida. La radiografía de esta situación actual ha permitido acercarnos a la percepción de los alumnos, de los profesionales y de los profesores, lo que resulta valioso para rediseñar los procesos formativos iniciales y permanentes de los futuros psicólogos.

Palabras-clave. Competencias académicas y profesionales. Subcompetencias conceptuales, procedimentales y actitudinales. 


\section{Introducción}

Una de las líneas recientes de trabajo del Consorcio para la Calidad de las Universidades Andaluzas, UCUA, está centrada en dotar a las Universidades de herramientas y de estrategias que puedan servir para validar la calidad de diversos aspectos de las mismas.

En el actual contexto de cambios, reformas y experimentación de nuevos perfiles de Titulación, promovidos por el marco del Espacio Europeo de la Educación Superior (EEES) una información relevante para poder tomar decisiones, actuales y futuras, proviene de la visión que los profesionales en activo tienen de la formación recibida durante el período de formación académica. La preocupación por esta retroalimentación (feedback) profesional, como fuente de información y de conocimiento sobre el ajuste o desajuste formativo, es una necesidad conocida, pero poco analizada.

La evaluación del grado de satisfacción que tienen los profesionales, desde su visión práctica, sobre la formación recibida en el período de formación universitaria puede ser efectuada desde diferentes parámetros, tales como la planificación y el desarrollo de los procesos de enseñanza-aprendizaje, el comportamiento docente y de la organización, la adecuación del perfil formativo de la titulación, etc. (De Miguel y cols., 2003; Fernández Sierra, 1996).

Entre ellos, nos centramos en el estudio del perfil de las competencias construidas, por considerar que es un elemento central y definitorio de la calidad del sistema formativo universitario, aunque estudiado de forma insuficiente. Para poder avanzar en este objetivo es necesario definir con más precisión el propio concepto de competencia, así como tener clara una posible categorización de las competencias.

\section{El modelo input-output de evaluación de las competencias}

El Modelo de Roe $(2002,2003)$ se basa en la necesidad de tener presente las diferentes competencias constitutivas de la práctica profesional para realizar un plan de formación adecuado. Plantea un modelo comprehensivo de competencias, como herramienta para construir un perfil profesional del psicólogo -aunque es extrapolable a otros campos profesionales-, integrando los modelos de input (curriculares) y output (práctica profesional) en la estructura 
conceptual de competencias que debe incorporar un profesional para una buena práctica. Este modelo asume que el perfil de competencias específicas de un profesional incluye tanto elementos tipo input (rasgos de personalidad, capacidades, conocimientos, habilidades y actitudes) como de elementos tipo output (competencias y subcompetencias).

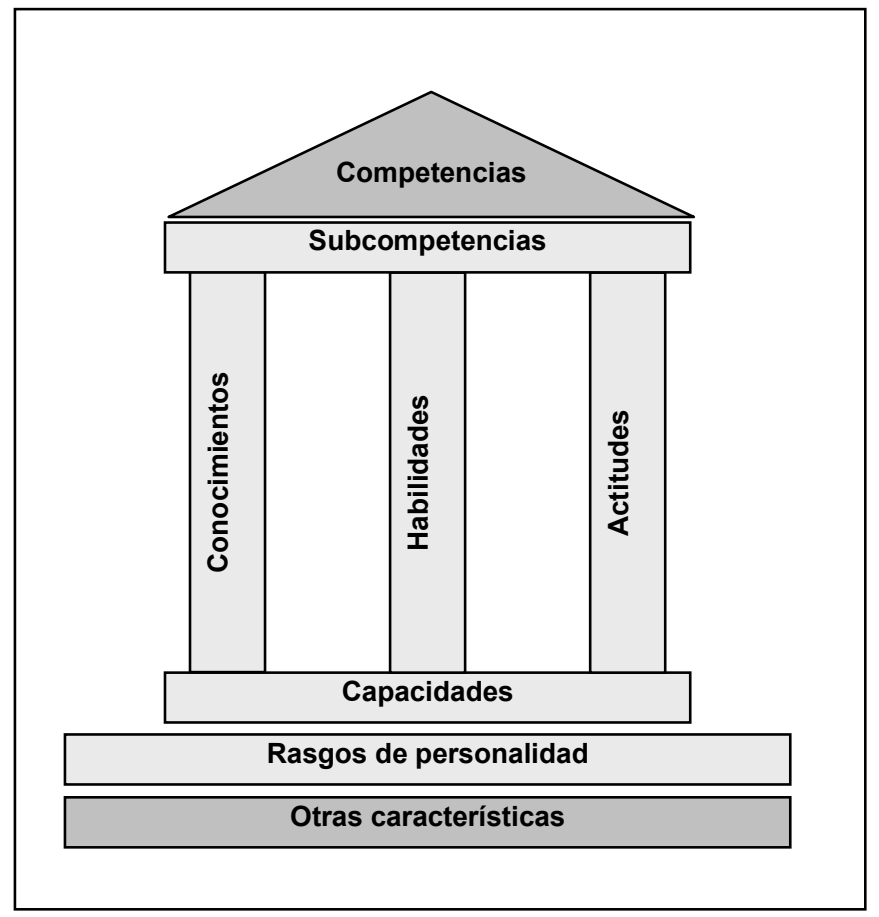

Figura 1. Modelo de Roe (Tomado de Roe, 2003, pág. 5)

En la práctica, este modelo considera dos tipos de elementos formativos que se construirían en dos momentos formativos diferentes y consecutivos, a saber: la formación universitaria inicial y la práctica profesional. Sin embargo, este modelo conceptual, a pesar de ser un heurístico importante para precisar diferentes conceptos y ordenarlos dentro del modelo, deja abiertas diferentes cuestiones pendientes de resolver:

1. ¿Cuál es la relación entre la formación input y output? ¿Se produce una integración automática entre ambos procesos formativos o, más bien, una sobreposición?

2. Las competencias o "saber hacer en la acción", ¿se consideran sólo de orden profesional?

3. ¿Es posible, en la práctica, evaluar las capacidades y los rasgos de personalidad de los titulados, a la hora de establecer un nivel de calidad del sistema? 
Para intentar superar estas limitaciones, nosotros hemos propuesto un modelo que tiene algunos elementos comunes con el de Roe (2002,2003), aunque parte de supuestos diferentes.

\section{Modelo de evaluación de las competencias académico-profesionales}

Las competencias para ejercer la profesión son definidas como un conjunto de conocimientos académico-profesionales integrados, que permiten un desempeño óptimo de los requerimientos profesionales (De la Fuente, 2003a, 2003b, en prensa). En este modelo teórico se asumen varios principios:

1. El conocimiento académico y el conocimiento profesional, siendo ambos necesarios para una buena formación que promueva un ejercicio profesional de excelencia, tienen formatos diferentes e interconectados, con transferencias entre sí, aunque no pertenecen al mismo continuo lineal sino a continuos diferentes y superpuestos. Por tanto, no son integrables automáticamente en el tiempo. Más bien, es necesario un trabajo consciente y autorregulado, por parte del sujeto, para que se produzca una reconstrucción integrada de ambos.

\section{Cuadro 1. Características del conocimiento académico (De la Fuente, 2003a, pág. 37).}

\section{-Saber:}

- qué: hechos, conceptos, principios, identificación de fenómenos y problemas

- por qué: principios, teorías, modelos explicativos

- para qué: objetivos, fines de la evaluación e intervención

\section{- Saber hacer:}

- que habría que hacer: aspectos

- cómo se debería hacer: principios, estrategias de resolución de problemas, secuencias

- investigación: problemas académicos

\section{Querer saber y saber hacer:}

- gusto por el conocimiento científico de modelos, teorías, investigaciones, evaluaciones, intervenciones.

- interés por las habilidades psicológicas prácticas; terapéuticas, preventivas, educativas...

- Conocimiento de orden teórico-aplicado: deductivo

- Pensamiento académico centrado, especialmente, en lo conceptual:

1. identificación de problemas

2. evaluación (en menor proporción)

3. intervención (en menor proporción) 
Cuadro 2. Características del conocimiento profesional (De la Fuente, 2003a, pág. 39).

- qué ocurre: hechos de la realidad profesional, normativas, datos directos, problemas...

- por qué ocurre: explicaciones profesionales concretas

\section{- Saber hacer:}

- tomar decisiones: para qué, qué, cómo, cuándo, dónde y quién, evaluar e intervenir

- ejecutar habilidades: evaluar, intervenir

- investigación: problemas referidos a la práctica profesional

\section{- Querer saber y saber hacer:}

- gusto por el conocimiento científico profesional de modelos, teorías, investigaciones, evaluaciones, intervenciones

- interés por las habilidades psicológicas prácticas; terapéuticas, preventivas, educativas...

- Conocimiento de orden ámbito aplicado-práctico: inductivo

- Formato de pensamiento: toma de decisiones para la resolución de problemas prácticos:

1. evaluación

2. intervención

2. La falta de construcción integrada de ambos tipos de conocimientos, debe provocar un sesgo competencial que impediría el óptimo desempeño en el contexto profesional, al producirse una ruptura epistemológica y práctica entre las competencias de orden factual, procedimental y actitudinal adquiridas en los contextos académico y profesional. De ahí, la importancia de efectuar una reconstrucción personal integrada.

Cuadro 3. Características del conocimiento académico-profesional integrado (De la Fuente, 2003a, pág. 40).

\section{-Saber:}

- qué ocurre: hechos de la realidad académica y profesional integrados.

- por qué ocurre: explicaciones teórico-practicas y prácticas-teóricas.

\section{- Saber hacer:}

- Toma de decisiones: resolución de problemas, partiendo de la experiencia y del conocimiento académico, de forma integrada:
1. identificación
2. evaluación
3. intervención

-Habilidades de identificación, evaluación e intervención....

-Investigación: producir propia investigación en contraste y coordinación con la investigación complementaria (académica o profesional).

\section{- Querer saber y saber hacer:}

- Gusto por el conocimiento integrado de orden teórico-práctico y práctico-teórico.

- Interés por la producción de conocimiento del propio ámbito y la contrastación con el conocimiento del otro ámbito.

- Conocimiento de orden: deductivo-inductivo e inductivo-deductivo, integrados 
- Formato de pensamiento investigativo de toma de decisiones:

1. detección del problema; 2. identificación; 3. evaluación ; 4. intervención; 5. evaluación;

6. retroalimentación

3. Las competencias (saber hacer en la acción) son de carácter académico y profesional, incluyendo cada una de ellas los saberes (subcompetencias conceptuales), las habilidades (subcompetencias procedimentales) y las actitudes (subcompetencias actitudinales), de tal forma que, en la práctica, la solución de los problemas y de las situaciones profesionales lleva consigo la utilización combinada de las competencias académico-profesionales. Además, ambos de tipos de competencias no se pueden circunscribir a un ámbito curricular o profesional (input-output, en el modelo de Roe), si no más bien, entender que se deberían construir en ambos contextos, académico y profesional, de manera secuencial y reglada. Como este hecho no se produce, sino que se realiza un reparto implícito de los aprendizajes competenciales entre los citados ámbitos de input-outup, es muy difícil la construcción integrada de los procesos formativos que se producen en la Universidad y en el contexto Profesional Aplicado (De la Fuente, 2003b). En síntesis, el problema reside en que, en la práctica, cada contexto formativo se ha especializado en la formación de una tipología de competencias, sin crear espacios y acciones coordinadas suficientes para favorecer la construcción integrada de ambas.

\section{Delimitación de las competencias académico-profesionales}

Como anteriormente referimos, las competencias están referidas a comportamientos complejos, que llevan implícitos aprendizajes (otras subcompetencias) de orden conceptual, procedimental y actitudinal. Aunque somos conscientes de que el concepto de competencia profesional (Roe, 2002) es más amplio y puede englobar a otras subcompetencias de los tres tipos (conceptuales, procedimentales y actitudinales), para el caso que nos ocupa, el asimilar el concepto de competencia al de contenidos de aprendizaje, tiene la ventaja clasificatoria de que ayuda a generar repertorios de enseñanza, de aprendizaje y, por tanto, de tipología de competencias. De forma similar, el docente, el alumno o el profesional puede categorizar rápidamente las competencias, en términos de contenidos de aprendizaje propuestos y de las propias actividades de aprendizaje, diseñadas para su construcción (De la Fuente y cols. 2004). 
Competencias conceptuales: hechos, conceptos y principios (saber)

Las competencias de orden conceptual están referidas al conocimiento factual, es decir, a un saber de hechos, conceptos y principios, entre otros, que se puede construir, tanto en el ámbito académico como profesional:

- Los hechos se refieren a acontecimientos o sucesos relevantes a un objeto de estudio dado. Un hecho académico puede ser las fases de evolución de una disciplina. Un hecho profesional puede ser el conocimiento de la prevalencia de una enfermedad en una zona dada. La mayoría de los hechos que un Titulado debe construir tienen ambos componentes combinados.

- Los conceptos se refieren al entramado de terminología, vocabulario, construcciones teóricas de la realidad académica o profesional. El actual concepto de la Psicología, como ciencia, es un concepto académico, mientras que el concepto de atención a la diversidad en el Real Decreto que regula la Atención a Discapacitados, es un concepto profesional.

- Los principios son elaboraciones descriptivas, explicativas y predictoras de los fenómenos que cada campo de estudio o aplicado elabora. El Principio de Premack o la Ley de Thorndike, en Psicología, son enunciados académicos que sirven para explicar, evaluar e intervenir en problemas psicológicos. El principio de que "cada maestrillo tiene su librillo" es un enunciado profesional que explica y predice el comportamiento docente en las aulas.

Competencias procedimentales: procedimientos (saber hacer)

Estas competencias están referidas al saber ejecutable o saber hacer de diferente tipo. Es de destacar que cualquiera de estas competencias, al igual que las demás, podemos considerarlas como un contínuum, a través del cual el sujeto puede ir avanzando, en los ámbitos de formación académico y profesional, no de manera excluyente, sino complementaria. Este tipo de saber es tan diverso como los repertorios implícitos en cada dimensión del desarrollo humano: 
- El saber hacer personal consiste en un conocimiento competencial dirigido a saber realizar acciones de orden personal. Ejercer autorregulación mientras se estudia es un saber hacer académico. Ejercer autocontrol mientras se realiza una entrevista clínica es un saber hacer profesional.

- El saber hacer social está referido a un conocimiento competencial que permite desenvolverse adecuadamente en situaciones sociales. Trabajar en equipo, en clase para hacer un trabajo, es un saber hacer académico. Coordinar y dirigir un equipo de trabajo en una sección de una empresa es un saber hacer profesional.

- El saber hacer físico-motriz es un conocimiento que permite efectuar acciones diversas, de tipo físico y motoriz. Escribir un trabajo en el ordenador, es un saber hacer académico (también con un componente cognitivo-lingüístico). Efectuar una presentación en ordenador para presentar un proyecto de trabajo a una administración es un saber hacer profesional.

- El saber hacer cognitivo-lingüistico hace mención al saber utilizar las habilidades de orden superior o cognitivo-lingüísticas. Analizar y efectuar una síntesis conceptual sobre el contenido de un libro científico es un saber hacer académico. Efectuar una sesión de trabajo, a través de la explicación de un análisis de la conducta, y la defensa de las hipótesis de intervención, es un saber hacer profesional.

Competencias actitudinales: actitudes, valores y normas (querer saber y querer saber hacer)

Estas competencias son las que delimitan el conocimiento actitudinal de los sujetos. Delimitan si han construido adecuadamente las actitudes, los valores y las normas, referidas a los saberes anteriores, esto es, el querer saber y el querer saber hacer. Este tipo de aprendizaje es el más difícil de ayudar a instaurar en los sujetos de los tres.

- Las actitudes son las competencias que comprenden el interés, gusto o disfrute, por una problemática dada, un objeto de estudio o un aspecto de la realidad. Disfrutar con el aprendizaje de las leyes del comportamiento es una actitud académica. Tener gusto por la actualización científica permanente en el trabajo aplicado es una actitud profesional. 
- Los valores son aquellas competencias que hacen que los sujetos efectúen juicios acordes a un modelo o código ético-profesional dado. El respeto a los diferentes posicionamientos psicológicos y teóricos dados es un valor académico. La defensa de los derechos éticos de un usuario dado, es un valor profesional.

- Las normas son las competencias que permiten a los sujetos tomar decisiones y comportarse acorde con esa elaboración o construcción personal. El comportamiento ético de no copiar trabajos de otros se refiere al cumplimento de una norma ética académica. El tomar decisiones para respetar la integridad y los derechos que asisten a una persona, es un comportamiento de norma ética profesional.

\section{Objetivos de la investigación}

A partir del anterior planteamiento conceptual integrado, nos planteamos los siguientes objetivos:

1. Elaborar una distribución de frecuencias con las competencias más y menos construidas por los profesionales.

2. Comparar las competencias que se construyen preferentemente en la Universidad, en el Campo Profesional y en ambos contextos, conjuntamente.

\section{MÉTODO}

\section{Participantes}

Participaron un total 76 sujetos (94 estudiantes, 34 profesores de universidad y 24 profesionales), de diferente sexo (42 masculino y 80 femenino), con distinta titulación (80 no licenciados, 28 licenciados y 20 doctores) y que habían finalizado en diferentes momentos la carrera (en último curso 96 sujetos, en los últimos diez años 16 sujetos y más de diez años 14 sujetos), con diferentes especialidades (16 de clínica, 18 de educativa, 8 de organizacional y 4 de otra), puestos actuales ( 8 no universitarios, 24 universitarios y 8 de empresa) y nivel de experiencia profesional (76 sujetos sin experiencia, 20 sujetos hasta 10 años, 10 sujetos hasta 20 años y 3 sujetos hasta 30 años).

\section{Instrumentos}


Para esta investigación utilizamos la Escala para la Evaluación de la Formación recibida, por los profesionales, versión. 1.00 (De la Fuente, 2004). Los datos de validez y fialibidad son aceptables y se recogen en el Informe UCUA. Está diseñada para recoger la percepción de los profesionales sobre el grado en que la formación recibida en la Universidad y en la posterior Actividad Profesional, ha ayudado al sujeto a construir cada una de las 130 competencias. Su estructura racional inicial delimitaba los aspectos a evaluar que se enumeran a continuación.

1. Competencias académicas básicas:

- Competencias cognitivo-lingüísticas instrumentales básicas (39 items)

- Competencias sociopersonales básicas (12 items)

2. Competencias de intervención profesional:

- Competencias cognitivo-lingüísticas instrumentales aplicadas (23 ítems)

- Competencias cognitivo-lingüísticas avanzadas aplicadas (31 ítems)

- Competencias sociopersonales aplicadas (24 ítems)

Cada tipología de competencias lleva implícitas diferentes categorías de subcompetencias: $\quad$ 1. saber: hechos, conceptos y principios.

2. querer saber: actitudes, valores y normas sobre el saber.

3. saber hacer: habilidades y destrezas propias de los procedimientos.

4. querer saber hacer: actitudes, valores y normas sobre el saber hacer.

La estructura empírica, obtenida en los análisis factoriales exploratorios efectuados en la primera versión experimental del instrumento, clasifica a cada ítem a partir de dos parámetros: 1. conocimiento académico y profesional, y 2. subcompetencia conceptual, procedimental y actitudinal. Esto permite una doble clasificación para cada ítem tal y como se detalla a la derecha del mismo (ver Anexo 1).

Los aspectos a cumplimentar en cada competencia son dos, dado que se solicita al sujeto que conteste el grado de construcción de esa competencia, con un rango tipo likert, de 1 (nada) a 5 (mucho) en la columna de la Universidad (titulación) y en la Actividad Profesional (práctica aplicada).

\section{Procedimiento}

A partir de la elaboración del instrumento de competencias académico-profesionales, efectuamos la versión electrónica del mismo para cumplimentarla de manera on-line. Para tal fin, establecimos dos niveles de evaluación, importantes a la hora de recoger la información: 
1. Preguntas cerradas. Estas preguntas estaban referidas a diferentes aspectos de la muestra a evaluar. Permiten recoger información de la Titulación y establecer posibles comparaciones normativas con Titulaciones de otras Universidades.

1.1. Variables de los sujetos (independientes).

1) Datos personales: edad y género.

2) Datos académicos: titulación, universidad, formación recibida, etc.

3) Datos profesionales: puesto actual, experiencia o perfil profesional.

1.2. Variables de valoración general de la carrera: satisfacción académica y profesional, respecto de a la formación recibida en la Titulación.

1.3. Variables de las competencias (variables dependientes). Referidas al grado de construcción de las competencias, ya enumeradas con anterioridad.

2. Preguntas abiertas. Pretendían dejar abierta la posibilidad de que los sujetos viertan información sobre los aspectos que la cumplimentación de la Escala les sugería o para hacer algunas propuestas de mejora.

El procedimiento para la obtención de los datos recogidos se efectuó de manera online, de manera coherente con las tendencias evaluadoras basadas en las nuevas tecnologías (Cook, Health y Thomson, 2000; Shannon y Bradshaw, 2002; Sheehan y Hoy, 1999; Smith, 1997). La herramienta en-línea UCUA permite la evaluación de las competencias académicoprofesionales en cualquier titulación Toda la información de la cumplimentación queda grabada en el lugar web habilitado por el software. La importación de los resultados en formato de bases de datos genérica y Excel permite la transformación o el procesamiento estadístico posterior con SPSS 10.0 (Pérez, 2004).

\section{Análisis estadísticos}

Esencialmente se realizaron análisis descriptivos e inferenciales, con el fin de mostrar los perfiles generales de construcción de las competencias en ambos ámbitos formativos, así como las diferencias significativas existentes entre ellos.

\section{Resultados}

Competencias totales construidas según el contexto formativo (Titulación y Aplicado) 
En general, las competencias construidas se sitúan entre regular y bastante, habida cuenta del rango de respuesta (1-5) en ambos contextos, aunque es mayor en el contexto de formación aplicado (resp. 2) que en el de formación de la titulación (resp. 1), con un efecto principal significativo, $\mathrm{F}(1,59)=10.48 \quad(\mathrm{p}<.002)$ en el anova efectuado, a favor de la media de competencias construidas en el contexto profesional aplicado (ver Tabla 1).

Tabla 1. Resultados descriptivos de las competencias totales construidas

\begin{tabular}{llllllll}
\hline Respuesta & $N$ & media & $d t$ & mínimo & máximo & error & post \\
Resp1 (Titulación) & 46 & 3.14 & $(.63)$ & 2.01 & 4.68 & 0.093 & $2>1 * *$ \\
Resp2 (Aplicado) & 15 & 3.80 & $(.82)$ & 1.82 & 4.64 & 0.211 & \\
Total & 61 & 3.30 & $(.73)$ & 1.82 & 4.68 & 0.094 & \\
& & & & & & &
\end{tabular}

Competencias académicas (dimensión 2) y profesionales (dimensión 1) construidas, en el contexto de la Titulación (Respuest1) y Aplicado (Respuest2)

El anova efectuado mostró un efecto principal, $F(2,59)=7.86, \mathrm{p}<.0000$, a favor de la media de competencias del contexto aplicado (respuest2). El análisis posterior puso de manifiesto, a través del siguiente efecto estadístico significativo aparecido en el anova, $\mathrm{F}(1,60)=12.58$, $\mathrm{p}<.001$, la existencia de una mayor construcción de competencias profesionales en el ámbito aplicado. Sin embargo, no hay diferencias significativas en cuanto a los contextos en los que construyen las competencias académicas.

Tabla 2. Competencias académicas y profesionales construidas

\begin{tabular}{lllll}
\hline Dimensión & Respuesta & $N$ & Media & $d t$ \\
1. C. Profesional & 1. Titulación & 47 & 3.09 & $(.70)$ \\
& 2. Aplicado & 15 & 3.91 & $(.98)$ \\
& total & 62 & 3.29 & $(.85)$ \\
& & & & \\
2. C. Académico & 1. Titulación & 47 & 3.34 & $(.58)$ \\
& 2. Aplicado & 15 & 3.59 & $(.70)$ \\
& total & 62 & 3.40 & $(.62)$ \\
\hline
\end{tabular}

Subcompetencias construidas (conceptuales, procedimentales y actitudinales) en cada contexto formativo

Subcompetencias construidas en la Titulación 
En este contexto formativo se construyen más las competencias conceptuales y actitudinales. Los resultados aparecidos en los análisis de diferencias de medias apareadas muestran, a la derecha de la Tabla, la significación estadística de las diferencias. De manera específica, en la segunda parte de la Tabla aparecen con más construidas las competencias conceptuales y actitudinales académicas en el contexto formativo de la titulación. La menor construcción está referida a las competencias de orden procedimental (saber hacer), tanto académicas como profesionales (ver Tabla 3).

Tabla 3. Subcompetencias construidas en la Titulación

\begin{tabular}{lllllll}
\hline Subcompetencia & $N$ & mínimo & máximo & Media & $d t$ & post \\
& & & & & & \\
1. Procedimental & 51 & 1.59 & 4.68 & 2.96 & $(.71)$ & $3>1^{* * * * *}$ \\
2. Actitudinal & 58 & 1.46 & 4.63 & 3.04 & $(.76)$ & $3>2^{*}$ \\
3. Conceptuales & 57 & 2.29 & 4.97 & 3.57 & $(.61)$ & \\
& & & & & & \\
& & & & & & \\
\hline 1. Proced. académicos & 61 & 1.00 & 5.00 & 2.06 & $(1.13)$ & $6>5$ **** \\
2. Proced. profesionales & 52 & 1.57 & 4.67 & 2.97 & $(.70)$ & $6>4^{* *}$ \\
3. Concept. profesionales & 62 & 1.25 & 4.75 & 3.29 & $(.83)$ & $6>3^{* * * *}$ \\
4. Act. profesionales & 59 & 1.32 & 4.64 & 3.37 & $(.77)$ & $6>2^{* * * *}$ \\
5. Act. académicos & 58 & 1.46 & 4.63 & 3.40 & $(.76)$ & $6>1^{* * * *}$ \\
6. Concept. académicos & 57 & 2.29 & 5.00 & 3.61 & $(.61)$ & \\
& & & & & &
\end{tabular}

Subcompetencias construidas en la práctica profesional

En este contexto formativo, la construcción de competencias se produce de manera más equilibrada, al no aparecer diferencias estadísticamente significativas en los análisis de diferencias de medias apareadas. De manera específica, los resultados recogidos en la segunda parte de la Tabla, muestra que se construyen más las competencias actitudinales académicas y el conocimiento conceptual y procedimental de orden profesional. Cabe destacar la menor construcción de los conocimientos y los procedimientos académicos (ver Tabla 4)

Tabla 4. Subcompetencias construidas en el ámbito aplicado

\begin{tabular}{lllllll}
\hline Subcompetencia & $N$ & mínimo & máximo & Media & $d t$ & post \\
& 21 & 1.68 & 4.97 & 3.76 & $(.78)$ & n.s. \\
1. Conceptual & 18 & 1.44 & 4.86 & 3.78 & $(1.12)$ & \\
2. Procedimental & 17 & 1.29 & 4.83 & 3.89 & $(.86)$ & \\
3. Actitudinal & 21 & 1.00 & 5.00 & 3.28 & $(1.27)$ & $1<2,3^{*}$ \\
\hline & & & & & &
\end{tabular}




$\begin{array}{lllllll}\text { 2. Concept. académicos } & 21 & 1.71 & 4.97 & 3.75 & (.78) & 1<4,5,6^{* * * * *} \\ \text { 3. Actit. profesionales } & 18 & 1.23 & 4.82 & 3.77 & (.98) & \\ \text { 4. Proced. profesionales } & 18 & 1.46 & 4.89 & 3.80 & (1.13) \\ \text { 5. Concept. pofesionales } & 21 & 1.25 & 5.00 & 3.83 & (1.02) \\ \text { 6. Actitud. académicas } & 17 & 1.29 & 4.83 & 3.89 & (.86)\end{array}$

Subcompetencias especificas construidas en cada contexto formativo

Subcompetencias específicas construidas en la Titulación

1) Subcompetencias conceptuales específicas

El listado de la Tabla 5 muestra el orden en la construcción de este tipo de subcompetencias. Cabe destacar la mayor construcción de las competencias cognitivo-lingüísticas básicas, así como la poca construcción de las subcompetencias referidas al conocimiento del segundo idioma, la profesión en otros países o el uso de bases de datos relevantes (ver anexo para los ítems concretos). 
Tabla 5. Subcompetencias conceptuales específicas

Estadisticos descriptiv os

\begin{tabular}{|c|c|c|c|c|c|}
\hline & $\mathrm{N}$ & Mínimo & Máximo & Media & Desv. típ. \\
\hline VAR067 & 63 & 1,00 & 5,00 & 2,1746 & 1,36239 \\
\hline VAR109 & 62 & 1,00 & 5,00 & 2,2903 & 1,24647 \\
\hline VAR108 & 61 & 1,00 & 5,00 & 2,4590 & 1,27245 \\
\hline VAR071 & 63 & 1,00 & 5,00 & 2,6190 & 1,43041 \\
\hline VAR058 & 64 & 1,00 & 5,00 & 2,8438 & 1,15770 \\
\hline VAR069 & 63 & 1,00 & 5,00 & 2,9524 & 1,48572 \\
\hline VAR052 & 64 & 1,00 & 5,00 & 3,2031 & 1,26214 \\
\hline VAR035 & 64 & 1,00 & 5,00 & 3,2187 & 1,04606 \\
\hline VAR098 & 62 & 1,00 & 5,00 & 3,2258 & 1,01496 \\
\hline VAR012 & 70 & 1,00 & 5,00 & 3,2429 & 1,06914 \\
\hline VAR080 & 63 & 1,00 & 5,00 & 3,2540 & 1,19094 \\
\hline VAR070 & 63 & 1,00 & 5,00 & 3,2857 & 1,32505 \\
\hline VAR040 & 66 & 1,00 & 5,00 & 3,2879 & 1,19955 \\
\hline VAR053 & 64 & 1,00 & 5,00 & 3,2969 & 1,24314 \\
\hline VAR005 & 70 & 1,00 & 5,00 & 3,3429 & 1,11493 \\
\hline VAR077 & 63 & 1,00 & 5,00 & 3,3968 & 1,00867 \\
\hline VAR099 & 62 & 1,00 & 5,00 & 3,4032 & 1,10824 \\
\hline VAR081 & 63 & 1,00 & 5,00 & 3,4444 & 99641 \\
\hline VAR020 & 70 & 1,00 & 5,00 & 3,4714 & 1,08643 \\
\hline VAR011 & 70 & 1,00 & 5,00 & 3,4857 & 1,12601 \\
\hline VAR076 & 62 & 2,00 & 5,00 & 3,5000 & 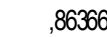 \\
\hline VAR072 & 63 & 1,00 & 5,00 & 3,5079 & 1,34252 \\
\hline VAR010 & 70 & 2,00 & 5,00 & 3,5143 & ,97420 \\
\hline VAR054 & 64 & 1,00 & 5,00 & 3,5312 & 1,05362 \\
\hline VAR079 & 62 & 1,00 & 5,00 & 3,5484 & 93524 \\
\hline VAR073 & 63 & 1,00 & 5,00 & 3,5714 & 1,22756 \\
\hline VAR055 & 64 & 1,00 & 5,00 & 3,5938 & 95483 \\
\hline VAR078 & 61 & 1,00 & 5,00 & 3,6393 & 94926 \\
\hline VAR037 & 66 & 1,00 & 5,00 & 3,6667 & 1,02782 \\
\hline VAR025 & 69 & 2,00 & 5,00 & 3,7246 & 90560 \\
\hline VAR008 & 70 & 1,00 & 5,00 & 3,7429 & 1,00269 \\
\hline VAR019 & 70 & 1,00 & 5,00 & 3,7571 & 1,08261 \\
\hline VAR007 & 70 & 2,00 & 5,00 & 3,7714 & 83703 \\
\hline VAR038 & 66 & 1,00 & 5,00 & 3,7727 & 1,03471 \\
\hline VAR009 & 70 & 2,00 & 5,00 & 3,8143 & ,88944 \\
\hline VAR004 & 70 & 1,00 & 5,00 & 3,9857 & 85961 \\
\hline VAR002 & 70 & 1,00 & 5,00 & 4,0571 & ,86620 \\
\hline VAR003 & 70 & 2,00 & 5,00 & 4,1000 & 78297 \\
\hline VAR006 & 70 & 2,00 & 5,00 & 4,1429 & 74767 \\
\hline $\mathrm{N}$ válido(según lista) & 57 & & & & \\
\hline
\end{tabular}

2) Subcompetencias procedimentales específicas

Las competencias más construidas se refieren a los aspectos generales de la conceptuación e identificación psicológica, tal y como refleja la Tabla 6. Las menos construidas son las referidos a procesos de adaptación, cambio y respuesta a las demandas en las situaciones laborales, que requieren un gran número de habilidades (ver anexo para los ítems concretos). 
Estadísticos descriptivos

\begin{tabular}{|c|c|c|c|c|c|}
\hline & $\mathrm{N}$ & Mínimo & Máximo & Media & Desv. típ. \\
\hline VAR125 & 62 & 1,00 & 5,00 & 2,0000 & 1,18737 \\
\hline VAR065 & 63 & 1,00 & 5,00 & 2,1587 & 1,15293 \\
\hline VAR124 & 62 & 1,00 & 5,00 & 2,3710 & 1,16273 \\
\hline VAR115 & 62 & 1,00 & 5,00 & 2,4032 & 1,24742 \\
\hline VAR066 & 63 & 1,00 & 5,00 & 2,4286 & 1,22756 \\
\hline VAR118 & 61 & 1,00 & 5,00 & 2,4426 & 1,08819 \\
\hline VAR110 & 61 & 1,00 & 5,00 & 2,4590 & 1,37324 \\
\hline VAR063 & 62 & 1,00 & 5,00 & 2,4677 & 1,30218 \\
\hline VAR064 & 63 & 1,00 & 5,00 & 2,4762 & 1,34233 \\
\hline VAR123 & 62 & 1,00 & 5,00 & 2,4839 & 1,14150 \\
\hline VAR120 & 62 & 1,00 & 5,00 & 2,5000 & 1,21129 \\
\hline VAR113 & 62 & 1,00 & 5,00 & 2,6452 & 1,28161 \\
\hline VAR061 & 63 & 1,00 & 5,00 & 2,6508 & 1,20695 \\
\hline VAR117 & 62 & 1,00 & 5,00 & 2,6935 & 1,09528 \\
\hline VAR059 & 63 & 1,00 & 5,00 & 2,6984 & 1,17274 \\
\hline VAR068 & 63 & 1,00 & 5,00 & 2,7619 & 1,38790 \\
\hline VAR086 & 63 & 1,00 & 5,00 & 2,7619 & 1,11752 \\
\hline VAR116 & 62 & 1,00 & 5,00 & 2,7903 & 1,10345 \\
\hline VAR094 & 62 & 1,00 & 5,00 & 2,8065 & 1,09901 \\
\hline VAR033 & 67 & 1,00 & 5,00 & 2,8358 & 1,16251 \\
\hline VAR036 & 66 & 1,00 & 5,00 & 2,8485 & 1,23091 \\
\hline VAR119 & 61 & 1,00 & 5,00 & 2,8689 & 1,25798 \\
\hline VAR093 & 62 & 1,00 & 5,00 & 2,8710 & 1,13778 \\
\hline VAR062 & 63 & 1,00 & 5,00 & 2,8730 & 1,23774 \\
\hline VAR114 & 62 & 1,00 & 5,00 & 2,8871 & 1,25587 \\
\hline VAR088 & 63 & 1,00 & 5,00 & 2,9048 & 1,22756 \\
\hline VAR121 & 62 & 1,00 & 5,00 & 2,9516 & 1,31108 \\
\hline VAR122 & 61 & 1,00 & 5,00 & 2,9672 & 1,23784 \\
\hline VAR095 & 62 & 1,00 & 5,00 & 2,9677 & 1,05532 \\
\hline VAR085 & 61 & 1,00 & 5,00 & 2,9836 & ,88491 \\
\hline VAR089 & 63 & 1,00 & 5,00 & 2,9841 & 1,09974 \\
\hline VAR047 & 64 & 1,00 & 5,00 & 3,0000 & 1,15470 \\
\hline VAR112 & 61 & 1,00 & 5,00 & 3,0328 & 1,44876 \\
\hline VAR026 & 68 & 1,00 & 5,00 & 3,0588 & 94446 \\
\hline VAR087 & 63 & 1,00 & 5,00 & 3,0794 & 1,16815 \\
\hline VAR090 & 63 & 1,00 & 5,00 & 3,0952 & 1,14602 \\
\hline VAR102 & 62 & 1,00 & 5,00 & 3,0968 & 1,12657 \\
\hline VAR027 & 69 & 1,00 & 5,00 & 3,1014 & 1,07300 \\
\hline VAR100 & 62 & 1,00 & 5,00 & 3,1452 & 1,21259 \\
\hline VAR034 & 67 & 1,00 & 5,00 & 3,1642 & 1,09540 \\
\hline VAR091 & 62 & 1,00 & 5,00 & 3,1774 & 1,01665 \\
\hline VAR096 & 62 & 1,00 & 5,00 & 3,1774 & 1,03265 \\
\hline VAR060 & 64 & 1,00 & 5,00 & 3,1875 & 1,05221 \\
\hline VAR029 & 68 & 1,00 & 5,00 & 3,1912 & 1,04034 \\
\hline VAR022 & 69 & 1,00 & 5,00 & 3,2029 & 1,02297 \\
\hline VAR043 & 66 & 1,00 & 5,00 & 3,2424 & 1,11024 \\
\hline VAR045 & 64 & 1,00 & 5,00 & 3,2656 & 1,17165 \\
\hline VAR044 & 66 & 1,00 & 5,00 & 3,2727 & 1,14416 \\
\hline VAR041 & 66 & 1,00 & 5,00 & 3,2879 & 1,22494 \\
\hline VAR031 & 66 & 1,00 & 5,00 & 3,3182 & 1,04010 \\
\hline VAR028 & 69 & 1,00 & 5,00 & 3,3188 & 1,05011 \\
\hline VAR101 & 62 & 1,00 & 5,00 & 3,3226 & 1,15623 \\
\hline VAR032 & 67 & 1,00 & 5,00 & 3,3582 & ,99547 \\
\hline VAR049 & 64 & 1,00 & 5,00 & 3,3750 & 1,27864 \\
\hline VAR021 & 69 & 2,00 & 5,00 & 3,3913 & 1,01775 \\
\hline VAR105 & 62 & 1,00 & 5,00 & 3,4032 & 1,07825 \\
\hline VAR092 & 62 & 1,00 & 5,00 & 3,4677 & 1,09721 \\
\hline VAR048 & 64 & 1,00 & 5,00 & 3,5000 & 1,00791 \\
\hline VAR023 & 69 & 1,00 & 5,00 & 3,6522 & ,98258 \\
\hline VAR030 & 67 & 1,00 & 5,00 & 3,6567 & ,96220 \\
\hline VAR042 & 66 & 1,00 & 5,00 & 3,7879 & 1,07439 \\
\hline VAR024 & 69 & 2,00 & 5,00 & 3,8551 & 87909 \\
\hline VAR046 & 63 & 1,00 & 5,00 & 3,9048 & 1,01146 \\
\hline $\mathrm{N}$ válido (según lista) & 51 & & & & \\
\hline
\end{tabular}


3) Subcompetencias actitudinales específicas

Estas subcompetencias muestran que las de mayor construcción están referidas al compromiso ético con el conocimiento y con los derechos de los usuarios (ver Tabla 7). Destaca la menor puntuación de las actitudes de conocimiento de la profesión en otros países y la integración teórico-práctica del conocimiento (ver anexo para los ítems concretos).

\begin{tabular}{|c|c|c|c|c|c|}
\hline \multicolumn{6}{|c|}{ Estadísticos descriptiv os } \\
\hline & $\mathrm{N}$ & Mínimo & Máximo & Media & Desv. tip. \\
\hline VAR111 & 61 & 1,00 & 5,00 & 2,5082 & 1,44479 \\
\hline VAR103 & 62 & 1,00 & 5,00 & 2,8710 & 1,32422 \\
\hline VAR126 & 62 & 1,00 & 5,00 & 3,0806 & 1,33427 \\
\hline VAR104 & 61 & 1,00 & 5,00 & 3,0820 & 1,29480 \\
\hline VAR084 & 63 & 1,00 & 5,00 & 3,1270 & 1,21140 \\
\hline VAR074 & 63 & 1,00 & 5,00 & 3,1746 & 1,15758 \\
\hline VAR016 & 70 & 1,00 & 5,00 & 3,2429 & 1,26761 \\
\hline VAR127 & 62 & 1,00 & 5,00 & 3,2742 & 1,18970 \\
\hline VAR015 & 70 & 1,00 & 5,00 & 3,3000 & 99782 \\
\hline VAR075 & 63 & 1,00 & 5,00 & 3,3175 & 1,26778 \\
\hline VAR050 & 64 & 1,00 & 5,00 & 3,3437 & 1,15770 \\
\hline VAR017 & 70 & 1,00 & 5,00 & 3,3571 & 1,12978 \\
\hline VAR018 & 70 & 1,00 & 5,00 & 3,3857 & 1,03969 \\
\hline VAR105 & 62 & 1,00 & 5,00 & 3,4032 & 1,07825 \\
\hline VAR130 & 62 & 1,00 & 5,00 & 3,4194 & 1,20855 \\
\hline VAR020 & 70 & 1,00 & 5,00 & 3,4714 & 1,08643 \\
\hline VAR083 & 63 & 1,00 & 5,00 & 3,4921 & 99795 \\
\hline VAR082 & 63 & 1,00 & 5,00 & 3,5873 & 1,04163 \\
\hline VAR051 & 64 & 1,00 & 5,00 & 3,6719 & 1,15645 \\
\hline VAR013 & 70 & 1,00 & 5,00 & 3,7000 & 1,17152 \\
\hline VAR056 & 64 & 1,00 & 5,00 & 3,7031 & 98689 \\
\hline VAR057 & 63 & 1,00 & 5,00 & 3,7143 & 1,03843 \\
\hline VAR129 & 62 & 1,00 & 5,00 & 3,7419 & 95704 \\
\hline VAR019 & 70 & 1,00 & 5,00 & 3,7571 & 1,08261 \\
\hline VAR039 & 66 & 1,00 & 5,00 & 3,8182 & 1,03640 \\
\hline VAR128 & 61 & 1,00 & 5,00 & 3,8689 & 1,07200 \\
\hline VAR014 & 70 & 1,00 & 5,00 & 3,9286 & 1,13344 \\
\hline VAR106 & 62 & 1,00 & 5,00 & 3,9677 & 1,05632 \\
\hline $\mathrm{N}$ válido (seg ún lista) & 58 & & & & \\
\hline
\end{tabular}

Subcompetencias específicas construidas en el contexto profesional

1) Subcompetencias conceptuales específicas

Las subcompetencias más constuidas se refieren a la terminología de la profesión, la actualización científica y a las propias posibilidades y limitaciones personales. Las de menor construcción están referidas al conocimiento de la profesión de otros países o al conocimiento de bases de datos (ver Tabla 8). 
Estadisticos descriptiv os

\begin{tabular}{|c|c|c|c|c|c|}
\hline & $\mathrm{N}$ & Mínimo & Máximo & Media & Desv. típ. \\
\hline VAR067 & 22 & 1,00 & 5,00 & 2,2727 & 1,35161 \\
\hline VAR071 & 22 & 1,00 & 5,00 & 2,5909 & 1,56324 \\
\hline VAR108 & 21 & 1,00 & 5,00 & 2,6190 & 1,43095 \\
\hline VAR109 & 21 & 1,00 & 5,00 & 2,7143 & 1,41926 \\
\hline VAR002 & 28 & 1,00 & 5,00 & 2,9286 & 1,18411 \\
\hline VAR004 & 28 & 1,00 & 5,00 & 2,9286 & 1,30323 \\
\hline VAR072 & 22 & 1,00 & 5,00 & 3,0909 & 1,60087 \\
\hline VAR035 & 25 & 1,00 & 5,00 & 3,1600 & 1,24766 \\
\hline VAR058 & 23 & 1,00 & 5,00 & 3,2609 & 1,32175 \\
\hline VAR008 & 28 & 1,00 & 5,00 & 3,3214 & 1,38921 \\
\hline VAR003 & 28 & 1,00 & 5,00 & 3,3571 & 1,12922 \\
\hline VAR073 & 22 & 1,00 & 5,00 & 3,3६36 & 1,29267 \\
\hline VAR069 & 22 & 1,00 & 5,00 & 3,3636 & 1,73330 \\
\hline VAR009 & 28 & 1,00 & 5,00 & 3,4643 & 1,10494 \\
\hline VAR077 & 22 & 2,00 & 5,00 & 3,5000 & 1,05785 \\
\hline VAR070 & 22 & 1,00 & 5,00 & 3,5000 & 1,14434 \\
\hline VAR038 & 25 & 1,00 & 5,00 & 3,5600 & 1,19304 \\
\hline VAR098 & 21 & 1,00 & 5,00 & 3,6190 & 1,07127 \\
\hline VAR099 & 21 & 1,00 & 5,00 & 3,6667 & 1,35401 \\
\hline VAR012 & 28 & 1,00 & 5,00 & 3,6786 & 1,18801 \\
\hline VAR010 & 28 & 2,00 & 5,00 & 3,6786 & 81892, \\
\hline VAR079 & 22 & 1,00 & 5,00 & 3,6818 & 1,12911 \\
\hline VAR052 & 23 & 1,00 & 5,00 & 3,6957 & 1,45960 \\
\hline VAR053 & 23 & 1,00 & 5,00 & 3,6957 & 1,14554 \\
\hline VAR055 & 23 & 2,00 & 5,00 & 3,6957 & 1,06322 \\
\hline VAR011 & 28 & 1,00 & 5,00 & 3,7143 & 1,08379 \\
\hline VAR078 & 22 & 1,00 & 5,00 & 3,7273 & 1,27920 \\
\hline VAR080 & 22 & 1,00 & 5,00 & 3,7273 & 1,35161 \\
\hline VAR007 & 28 & 1,00 & 5,00 & 3,8214 & 1,21879 \\
\hline VAR054 & 23 & 1,00 & 5,00 & 3,8261 & 1,11405 \\
\hline VAR005 & 28 & 1,00 & 5,00 & 3,8571 & 1,17739 \\
\hline VAR020 & 28 & 1,00 & 5,00 & 3,8929 & 1,03062 \\
\hline VAR081 & 22 & 1,00 & 5,00 & 3,9091 & 1,01929 \\
\hline VAR076 & 22 & 2,00 & 5,00 & 3,9545 & 84387 \\
\hline VAR019 & 28 & 1,00 & 5,00 & 3,9643 & 88117, \\
\hline VAR040 & 25 & 1,00 & 5,00 & 4,0000 & 1,29099 \\
\hline VAR025 & 28 & 2,00 & 5,00 & 4,0714 & 1,08623 \\
\hline VAR006 & 28 & 1,00 & 5,00 & 4,0714 & 1,01575 \\
\hline VAR037 & 25 & 3,00 & 5,00 & 4,3200 & ,74833 \\
\hline $\mathrm{N}$ válido(seg ún lista) & 21 & & & & \\
\hline
\end{tabular}

\section{2) Subcompetencias procedimentales específicas}

Las subcompetencias menos construidas se refieren al trabajo en contextos internacionales y en otros países. También las referidas al asesoramiento a las organizaciones y a la implicación de los sujetos en el trabajo organizativo (ver Tabla 9). 
Jesús de la Fuente et al.

Estadísticos descriptivos

\begin{tabular}{|c|c|c|c|c|c|}
\hline & $\mathrm{N}$ & Mínimo & Máximo & Media & Desv. típ. \\
\hline VAR125 & 21 & 1,00 & 5,00 & 2,6667 & 1,68325 \\
\hline VAR110 & 21 & 1,00 & 5,00 & 2,9524 & 1,43095 \\
\hline VAR123 & 21 & 1,00 & 5,00 & 3,0000 & 1,48324 \\
\hline VAR033 & 26 & 1,00 & 5,00 & 3,3462 & 1,12933 \\
\hline VAR066 & 22 & 1,00 & 5,00 & 3,4545 & 1,33550 \\
\hline VAR118 & 21 & 1,00 & 5,00 & 3,4762 & 1,47034 \\
\hline VAR124 & 21 & 1,00 & 5,00 & 3,4762 & 1,47034 \\
\hline VAR119 & 21 & 1,00 & 5,00 & 3,4762 & 1,47034 \\
\hline VAR120 & 21 & 1,00 & 5,00 & 3,4762 & 1,36452 \\
\hline VAR068 & 22 & 1,00 & 5,00 & 3,5000 & 1,73891 \\
\hline VAR112 & 21 & 1,00 & 5,00 & 3,5238 & 1,36452 \\
\hline VAR122 & 21 & 1,00 & 5,00 & 3,5238 & 1,53685 \\
\hline VAR034 & 26 & 1,00 & 5,00 & 3,5385 & 1,39229 \\
\hline VAR091 & 22 & 1,00 & 5,00 & 3,5455 & 1,43849 \\
\hline VAR116 & 21 & 1,00 & 5,00 & 3,5714 & 1,36277 \\
\hline VAR117 & 21 & 1,00 & 5,00 & 3,5714 & 1,46872 \\
\hline VAR094 & 22 & 1,00 & 5,00 & 3,5909 & 1,18157 \\
\hline VAR036 & 25 & 1,00 & 5,00 & 3,6000 & 1,32288 \\
\hline VAR064 & 22 & 1,00 & 5,00 & 3,6364 & 1,46533 \\
\hline VAR088 & 22 & 1,00 & 5,00 & 3,6364 & 1,52894 \\
\hline VAR095 & 21 & 1,00 & 5,00 & 3,6667 & 1,35401 \\
\hline VAR113 & 21 & 1,00 & 5,00 & 3,6667 & 1,19722 \\
\hline VAR087 & 21 & 1,00 & 5,00 & 3,6667 & 1,35401 \\
\hline VAR101 & 21 & 1,00 & 5,00 & 3,6667 & 1,35401 \\
\hline VAR115 & 21 & 1,00 & 5,00 & 3,6667 & 1,27802 \\
\hline VAR121 & 21 & 1,00 & 5,00 & 3,6667 & 1,49443 \\
\hline VAR041 & 25 & 1,00 & 5,00 & 3,6800 & 1,40594 \\
\hline VAR049 & 23 & 1,00 & 5,00 & 3,6957 & 1,14554 \\
\hline VAR092 & 21 & 1,00 & 5,00 & 3,7143 & 1,38358 \\
\hline VAR100 & 21 & 1,00 & 5,00 & 3,7143 & 1,30931 \\
\hline VAR043 & 25 & 1,00 & 5,00 & 3,7200 & 1,24231 \\
\hline VAR032 & 26 & 1,00 & 5,00 & 3,7308 & 1,21845 \\
\hline VAR047 & 23 & 1,00 & 5,00 & 3,7391 & 1,09617 \\
\hline VAR027 & 28 & 1,00 & 5,00 & 3,7500 & 1,26564 \\
\hline VAR090 & 22 & 1,00 & 5,00 & 3,7727 & 1,41192 \\
\hline VAR021 & 28 & 1,00 & 5,00 & 3,7857 & 1,28689 \\
\hline VAR063 & 21 & 1,00 & 5,00 & 3,8095 & 1,28915 \\
\hline VAR096 & 21 & 1,00 & 5,00 & 3,8095 & 1,20909 \\
\hline VAR085 & 22 & 1,00 & 5,00 & 3,8182 & 1,25874 \\
\hline VAR046 & 23 & 1,00 & 5,00 & 3,8261 & 1,19286 \\
\hline VAR023 & 28 & 1,00 & 5,00 & 3,8571 & 1,17739 \\
\hline VAR086 & 22 & 1,00 & 5,00 & 3,8636 & 1,32001 \\
\hline VAR045 & 23 & 1,00 & 5,00 & 3,8696 & 1,09977 \\
\hline VAR065 & 22 & 1,00 & 5,00 & 3,9091 & 1,34196 \\
\hline VAR089 & 22 & 1,00 & 5,00 & 3,9091 & 1,34196 \\
\hline VAR062 & 22 & 1,00 & 5,00 & 3,9091 & 1,30600 \\
\hline VAR031 & 26 & 1,00 & 5,00 & 3,9231 & 1,23038 \\
\hline VAR022 & 28 & 1,00 & 5,00 & 3,9286 & 1,11981 \\
\hline VAR026 & 28 & 1,00 & 5,00 & 3,9286 & 1,33135 \\
\hline VAR048 & 23 & 1,00 & 5,00 & 4,0000 & 1,12815 \\
\hline VAR029 & 27 & 1,00 & 5,00 & 4,0000 & 1,20894 \\
\hline VAR044 & 25 & 1,00 & 5,00 & 4,0000 & 1,08012 \\
\hline VAR105 & 21 & 2,00 & 5,00 & 4,0000 & 1,09545 \\
\hline VAR114 & 21 & 1,00 & 5,00 & 4,0000 & 1,22474 \\
\hline VAR102 & 21 & 2,00 & 5,00 & 4,0000 & ,94868 \\
\hline VAR030 & 26 & 1,00 & 5,00 & 4,0385 & 1,07632 \\
\hline VAR060 & 23 & 1,00 & 5,00 & 4,0435 & 1,29609 \\
\hline VAR093 & 22 & 1,00 & 5,00 & 4,0455 & 1,25270 \\
\hline VAR028 & 28 & 2,00 & 5,00 & 4,0714 & 97861 \\
\hline VAR059 & 22 & 1,00 & 5,00 & 4,0909 & 1,47710 \\
\hline VAR061 & 22 & 1,00 & 5,00 & 4,0909 & 1,37699 \\
\hline VAR042 & 25 & 2,00 & 5,00 & 4,1200 & ,88129 \\
\hline VAR024 & 28 & 1,00 & 5,00 & 4,2857 & 1,01314 \\
\hline N válido (según lista) & 18 & & & & \\
\hline
\end{tabular}


3) Subcompetencias actitudinales específicas

Las subcompoetencias más deficitarias, una vez más se refieren a las actitudes de trabajo con otros países y profesionales de los mismos. Las actitudes más construidas son las referidas a las normas deontológicas de la profesión (ver Tabla 10).

Estadísticos descriptiv os

\begin{tabular}{|c|c|c|c|c|c|}
\hline & $\mathrm{N}$ & Mínimo & Máximo & Media & Desv. típ. \\
\hline VAR111 & 21 & 1,00 & 5,00 & 2,6667 & 1,46059 \\
\hline VAR126 & 21 & 1,00 & 5,00 & 3,5714 & 1,36277 \\
\hline VAR051 & 23 & 1,00 & 5,00 & 3,6522 & 1,26522 \\
\hline VAR018 & 28 & 1,00 & 5,00 & 3,7143 & 1,21281 \\
\hline VAR016 & 28 & 1,00 & 5,00 & 3,7500 & 1,26564 \\
\hline VAR082 & 21 & 1,00 & 5,00 & 3,7619 & 1,33809 \\
\hline VAR074 & 22 & 1,00 & 5,00 & 3,7727 & 1,41192 \\
\hline VAR103 & 21 & 1,00 & 5,00 & 3,8095 & 1,32737 \\
\hline VAR127 & 21 & 1,00 & 5,00 & 3,8095 & 1,16701 \\
\hline VAR015 & 28 & 1,00 & 5,00 & 3,8214 & 1,15642 \\
\hline VAR129 & 21 & 1,00 & 5,00 & 3,8571 & 1,38873 \\
\hline VAR130 & 21 & 1,00 & 5,00 & 3,8571 & 1,23635 \\
\hline VAR083 & 22 & 1,00 & 5,00 & 3,8636 & 1,12527 \\
\hline VAR020 & 28 & 1,00 & 5,00 & 3,8929 & 1,03062 \\
\hline VAR104 & 20 & 1,00 & 5,00 & 3,9000 & 1,16529 \\
\hline VAR056 & 23 & 2,00 & 5,00 & 3,9130 & ,99604 \\
\hline VAR039 & 25 & 1,00 & 5,00 & 3,9600 & 1,36870 \\
\hline VAR014 & 28 & 1,00 & 5,00 & 3,9643 & 1,13797 \\
\hline VAR019 & 28 & 1,00 & 5,00 & 3,9643 & 88117 \\
\hline VAR105 & 21 & 2,00 & 5,00 & 4,0000 & 1,09545 \\
\hline VAR084 & 22 & 1,00 & 5,00 & 4,0455 & 1,25270 \\
\hline VAR128 & 20 & 1,00 & 5,00 & 4,0500 & 1,27630 \\
\hline VAR017 & 28 & 1,00 & 5,00 & 4,0714 & 1,08623 \\
\hline VAR050 & 23 & 1,00 & 5,00 & 4,0870 & 1,12464 \\
\hline VAR057 & 22 & 2,00 & 5,00 & 4,1364 & 88884 \\
\hline VAR075 & 22 & 1,00 & 5,00 & 4,1364 & 1,20694 \\
\hline VAR013 & 28 & 1,00 & 5,00 & 4,1429 & 1,14550 \\
\hline VAR106 & 21 & 2,00 & 5,00 & 4,2381 & 99523 \\
\hline $\mathrm{N}$ válido(según lista) & 17 & & & & \\
\hline
\end{tabular}

\section{Discusión y conclusiones}

Los resultados encontrados han propiciado el acercamiento a una problemática digna de estudio. Nos han permitido constatar diferentes aspectos importantes, a nuestro modo de ver. En primer lugar, hemos constatado que, tal como habíamos propuesto en nuestro modelo de partida (De la Fuente, 2003; Roe, 2002, 2003), las competencias académicas y profesionales propuestas se construyen en los dos ámbitos formativos, de manera complementaria, aunque existe un desequilibrio o, más bien, una especialización formativa, en cada ámbito. 
En general, los sujetos opinan que en el contexto profesional-aplicado es donde se construye una mayor cantidad de competencias. La mayoría del conocimiento factual (saber) se construye en el ámbito de la Titulación, mientras que la construcción del conocimiento procedimental (saber hacer) se produce en el ámbito aplicado.

Pero la información más interesante proviene de la evaluación de las subcompetencias porque nos permite ahondar con mayor precisisón en los matices. Como hemos podido comprobar existen diferencias muy claras en el contexto formativo de la Titulación, con una mayor construcción de subcompetencias conceptuales académicas y actitudinales -el saber y el querer saber y hacer-, en detrimento de las de orden procedimental académico y, en general del conocimiento profesional de orden conceptual y procedimental. En el contexto aplicado, sin embargo, se construyen por excelencia las competencias conceptuales y procedimentales de orden profesional. Es destacable la baja puntuación obtenida por las competencias procedimentales académicas, tanto en el ámbito de la titulación como en el aplicado, lo que pondría de manifiesto un importante déficit formativo del saber hacer académico, imprescindible para una formación óptima e integración del conocimiento académico-profesional.

En el caso de las competencias específicas, los resultados son coincidentes con otros aparecidos con una muestra de orientadores escolares (De la Fuente, en prensa) y ponen de manifiesto las bondades y los déficits propios de la formación inicial y continua de los psicólogos como profesionales, especialemente en lo referido al ámbito internacional y a las competencias del saber hacer profesional, en algunos casos, no abordadas ni en la formación incial ni en la permanente (De la Fuente, 2000a).

No queremos finalizar este informe de investigación sin mencionar varias limitaciones importantes. En primer lugar, sabemos que es necesario seguir ampliando la muestra de nuestro estudio de cara a una mayor representatividad y generalización de los resultados, amén de una mayor validación de la versión experimental del instrumento de medida utilizado. En segundo lugar, debemos aclarar que en los análisis realizados hemos comprobado que los resultados generales presentados están modulados por las variables personales y profesionales de los sujetos, aspectos que no han sido objeto de este informe y deberán serlo en trabajos futuros. 
Los resultados nos llevan a considerar que esta línea de trabajo es muy provechosa, tanto en el presente como en el futuro. La radiografía de esta situación actual nos ha permitido acercarnos a la percepción de la formación recibida por los profesionales, profesores y alumnos como un criterio de calidad de la Titulación cursada. En el futuro, sería deseable seguir este criterio de evaluación para conocer si los cambios producidos por la implantación del Espacio Europeo de la Educación Superior han supuesto un incremento en el criterio de la Calidad formativa de las Titulaciones, por parte de los profesionales y alumnos aplicados. Desde la perspectiva de la formación profesional permanente, sería deseable que las organizaciones encargadas de actualizar a sus profesionales tuvieran presente este feedback importante que, a modo de screening, hemos aportado. Sigue siendo urgente un plan integrado y coordinado de formación inicial y permanente para nuestros profesionales.

\section{Agradecimientos}

Este trabajo se ha realizado gracias a la participación anónima de profesionales, alumnos y profesores, así como a la participación expresa del Colegio Oficial de Psicólogos y diversas Delegaciones Provinciales de la Junta de Andalucía.

\section{Referencias}

Cook, C., Health, F., y Thomson, R. (2000). A meta-analysis of response rates in Web - or Internet-based surveys. Educational \& Psychological Measurement, 60(6), 821-826.

De la Fuente, J. (2003a). ¿Por qué los alumnos no construyen un conocimiento académico y profesional integrado? Reflexiones para una investigación necesaria. Papeles del Psicólogo, 24 (86), 34-41.

De la Fuente, J. (2003b). Competencias académico-profesionales para la formación psicológica. Manuscrito sin publicar.

De la Fuente, J. (2004). Escala para la evaluación de la formación psicológica desde la perspectiva de los profesionales. Almería: RPI-18-04.

De la Fuente, J. (en prensa). La construcción de las competencias académico-profesionales para el asesoramiento educativo. En J. I. Pozo y C. Monereo (Coords), El asesoramiento educativo a exámen. Barcelona: Graó.

De la Fuente, J. y cols. (2004). Guía metodológica para la evaluación en-línea de la construcción del conocimiento profesional, promovido desde las titulaciones oficiales. Proyecto UCUA. UAL-11. Córdoba: UCUA. 
De Miguel, M. (Coord) (2003). Evaluación de la calidad de las titulaciones universitarias. Madrid: Ministerio de Educación, Cultura y Deporte.

Fernández Sierra, J. (1996). La evaluación del profesorado de la Universidad de Almería. Almería: Servicio de Publicaciones.

Pérez, C. (2004). Técnicas estadísticas con SPSS. Madrid: Pearson-PrenticeHall.

Proyecto EuroPsyT (2003). Una propuesta marco para la educación y formación del psicólogo en Europa. INFOCOP, 86, 65-76.

Roe, R. A. (2002).Competences-A key towars the integration of theory and practice in work psychology. Gedrag en Organisatie, 15, 203-224.

Roe, R. A. (2003). ¿Qué hace competente a un Psicólogo?. Papeles del Psicólogo, 24 (86), 112.

Shannon, D. M., y Bradshaw, C. C. (2002). A comparison fo response rate, response time, and costs of mail and electronic surveys. The Journal of Experimental Education, 70(2), 179-192.

Sheehan, K. B. y Hoy, M. G. (1999). Using e-mail to survey Internet users in the United Status: Methodology and assessment. Journal of Computer Mediated Commnunication, 4(3). From http://www.ascusc.org/jcmc/vol4/issue3/sheehan.html.

Smith, C. (1997). Casting the net: surveying the Internet population. Journal of Computer Mediated Communication, 4(3).

From: http://www.ascusc.org/jcmc/vol3/issue1/smith.html

\section{Anexo 1}

İtems de la ESCALA PARA LA EVALUACIÓN DE LA FORMACIÓN PSICOLÓGICA DESDE LA PERSPECTIVA DE LOS PROFESIONALES. Versión 1.00 (2004)

(C) Prof. Dr. Jesús de la Fuente Arias. Universidad de Almería (Spain)

Tipos de competencias que se evalúan:

$\mathrm{CA}=$ conceptual académico

$\mathrm{PA}=$ procedimental académico

$\mathrm{AA}=$ actitudinal académico
$\mathrm{CP}=$ conceptual profesional $\mathrm{PP}=$ procedimental profesional $\mathrm{AP}=$ actitudinal profesional

\section{COMPETENCIAS ACADÉMICAS BÁSICAS.}

Titul. Prof.

1. 1. Competencias cognitivo-linguísticas básicas.

Saber:

$$
\begin{aligned}
& \text { Hechos } \\
& \text { 1. Conocer aspectos de la cultura general suficientemente amplios. } \\
& \text { 2. Conocer la evolución histórica de la Psicología. }
\end{aligned}
$$$$
-\quad-
$$ 
Conceptos

3. Conocer los modelos teóricos explicativos de la psicología.

4. Conocer las estructuras y procesos psicofisiológicos relevantes para entender la conducta y los procesos fisiológicos.

5. Conocer los conocimientos básicos de la profesión.

6. Conocer la terminología científica propia del campo de la Psicol.

7. Conocer distintos métodos de evaluación, diagnóstico y tratamiento psicológico en los distintos ámbitos de la Psicología.

8.Conocer diferentes diseños de investigación para el trabajo Psicol..

\section{Principios}

9. Conocer los principios básicos del desarrollo psicológico y de los fenómenos educativos, de la personalidad y el funcionamiento psicopatológico, de los grupos y las organizaciones.

\section{Querer saber:}

Actitudes y valores

10. Mostrar interés por la cultura y el conocimiento.

11. Respetar la diversidad teórica y metodológica.

12. Valorar el conocimiento obtenido a partir de las distintas metodología científicas.

13. Valorar la profesión como campo de trabajo que tiene unas competencias específicas y concretas, diferenciadas de otro tipo de profesionales.

\section{Normas}

14. Tener un compromiso ético con el conocimiento.

\section{Saber hacer:}

Capacidad de aprender a aprender (autorregulación)

15. Planificar y controlar el proceso de aprendizaje de manera autónoma.

16. Autoevaluarse y reflexionar sobre el proceso de aprendizaje.

17. Aprender de los errores y realizar cambios prospectivos.

18. Utilizar estrategias de aprendizaje flexibles, ajustadas a los objetivos propuestos.

AP

AP

AP

AP

Análisis, síntesis e identificación

19. Conocer las principales fuentes de información y documentación.

20. Analizar, sintetizar y resumir información de documentos científico-profesionales.

21. Realizar análisis funcionales que vinculen distintos aspectos de los procesos psicológicos implicados entre sí.

Capacidad de organizar, planificar y tomar decisiones para resolver problemas

a) identificación:

22. Identificar las necesidades individuales, grupales, comunitarias, institucionales y organizacionales.

23. Identificar la conducta o el proceso psicológico objeto de estudio, sus variantes y las conductas o procesos vinculados con ellos.

24. Identificar el contexto en el que tiene lugar la conducta.

25. Identificar las variables explicativas causales de un problema psicológico dado.

26. Identificar y definir los problemas psicológicos en el ámbito 
de trabajo propio.

b) evaluación:

27. Generar alternativas para evaluar y diagnosticar problemas psicológicos.

28. Evaluar y valorar los resultados de una intervención psicológica.

c) intervención:

29. Generar alternativas para evaluar y resolver problemas psicológ.

30. Definir los objetivos de una intervención psicológica.

31. Elaborar estrategias de intervención psicológica de tipo individual, grupal o comunitario.

32. Elegir la técnica de intervención psicológica adecuada para alcanzar los objetivos propuestos.

33. Dominar estrategias y técnicas que permitan que individuos o grupos se involucren de modo activo en la intervención .

$$
\text { - }
$$$$
-\quad P P
$$$$
-\quad P P
$$$$
\text { d) seguimiento: }
$$

34. Establecer formas de control, evaluación y seguimiento de la intervención.

d) investigación:

35. Aplicar diseños de investigación que permitan deducir resultados psicológicamente relevantes y científicamente pertinentes.

36. Adquirir habilidades de toma de decisión sobre resultados profesionales y científicos.

\section{Querer saber hacer:}

Actitudes y valores

37. Mostrar interés por el estudio y puesta al día en la formación continua de la psicología.

38. Mostrar interés por la investigación y producción de nuevos datos en Psicología.

Normas

39. Poseer un compromiso ético en la realización de las tareas de investigación.

\subsection{Competencias personales básicas.}

Saber:

Hechos

40. Conocer las posibilidades y limitaciones personales.

Principios

41. Conocer las competencias personales que lleva consigo la profesión de psicólogo.

\section{Querer saber:}

42. Tener interés por la mejora personal.

\section{Saber hacer:}

Autorregulación y autocontrol personal 
Motivación de logro

44. Motivarse hacia el trabajo, ejerciendo resistencia a la

frustración.

45. Definir metas de mejora académica, personal y profesional.

Iniciativa y espíritu emprendedor

46. Proponer y reconocer la utilidad de la Psicología en distintos ámbitos de intervención.

47. Desarrollar iniciativas propias, destinadas a resolver

situaciones-problema de interés psicológico.

Preocupación por la calidad

48. Tener gusto por la calidad del trabajo realizado, como referente de la propia actuación.

\section{Querer saber hacer:}

Actitudes y valores

49. Tener inquietud por el éxito.

50. Tener una actitud emprendedora y de calidad en el trabajo.

Normas

51. Tener un compromiso ético en la consecución de logros personales.

\section{COMPETENCIAS DE INTERVENCIÓN PROFESIONAL.}

\subsection{Competencias cognitivo-lingüísticas instrumentales de intervención profesional.}

Saber:

Hechos

52. Conocer la problemática relevante del campo profesional en el que se va a trabajar.

53. Tener conocimiento de las revistas más relevantes en el área propia de intervención psicológica.

Conceptos

54. Conocer la terminología científica de las disciplinas más afines a la Psicología.

\section{Querer saber:}

Actitudes y valores

55. Tener interés por las aportaciones de otros campos a la Psicología y de ésta a ellos.

56. Mostrar una actitud de respecto a otras disciplinas científicas.

Normas

57. Cumplir de las normas éticas en el uso de la terminología científica y en la información del campo profesional.

\section{Saber hacer:}

Comunicación oral y escrita

58. Redactar conceptualmente un discurso y trasladarlo a un texto.

59. Redactar informes psicológicos destinados a usuarios individuales, servicios, empresas, instituciones, así como informes de investigac. 
técnicas de evaluación y diagnóstico psicológico.

61. Comunicar resultados psicológicos de forma oral adecuando

la presentación al destinatario/os de la misma.

PP

62. Dominar técnicas de presentación de datos (orales, informáticas,

otro tipo de tecnologías).

63. Tener habilidades de comunicación y persuasión.

64. Hablar en público correctamente.

65. Asesorar a otros profesionales.

66. Interesar a las personas o instituciones a las que vaya dirigido

el informe en la aplicabilidad de los resultados psicológicos.

PP

$\mathrm{PP}$

PP

PP

Conocimiento de segundo idioma

67. Utilizar una lengua extranjera (habitualmente, inglés).

CA

Habilidades básicas de manejo de ordenador

68. Manejo de la informática como usuario (procesador de textos, hojas de cálculo, etc.), así como de internet (búsquedas en la red, administración de correo electrónico, transferencia ficheros, etc.) 69. Manejar algún programa estadístico de uso habitual en Psicología (SPSS o similares).

PA

CA

Habilidades de gestión de información

70. Identificar fuentes de datos en Psicología.

71. Manejar bases de datos relevantes en Psicología (PsyClit,

Psicodoc, Medline, Current Contents, Social Sciences, Citation

Index, etc.).

72. Saber buscar documentación en una biblioteca o hemeroteca científica.

73. Planificar una búsqueda bibliográfica o de referencias.

\section{Querer saber hacer:}

\section{Actitudes y valores}

74. Mostrar interés por el aprendizaje de las competencias instrumentales, requisitas de la profesión.

Normas

75. Cumplir las normas deontológicas en el manejo de información $\mathrm{y}$ datos psicológicos.

\subsection{Competencias cognitivo-lingüísticas aplicadas a la intervención profesional.}

Saber:

Hechos

76.Conocer datos psicológicos científico-profesionales relevantes.

Conceptos

77.Conocer distintos diseños de investigación profesional.

78. Conocer los conceptos más utilizados y el vocabulario específico propio del campo profesional en el que se va a trabajar.

79. Conocer los modelos explicativos y conceptuales que la práctica profesional lleva consigo.

Principios

80. Conocer los principios psicológicos generados por el propio campo profesional.

\section{Querer saber:}


81. Respetar la diversidad profesional y la crítica ponderada a los avances científicos en la profesión.

Normas

82.Asumir un compromiso ético con los avances en el conocimiento científico psicológico.

\section{Saber hacer:}

Autoaprendizaje profesional

83.Tener autoconciencia del conocimiento adquirido y de las habilidades profesionales.

84. Trabajar de forma autónoma.

85. Aplicar de forma individual y activa los conocimientos y habilidades a la resolución de problemas psicológicos.

Aplicar el conocimiento a la práctica

86. Transferir el conocimiento académico a las diferentes situaciones reales provenientes de los distintos ámbitos específicos de intervención psicológica.

a) detección y explicación:

87. Detectar poblaciones de riesgo o interés.

88. Identificar y dar explicaciones de problemas en contextos reales.

b) evaluación:

89. Aplicar distintos métodos de evaluación y diagnóstico psicológicos al ámbito aplicado de la psicología en el que se trabaja (educativo, clínico y de la salud, sociocomunitario, jurídico y de las organizaciones, etc.).

c) intervención:

90. Aplicar estrategias y técnicas psicológicas en los ámbitos individual, grupal y comunitario.

d) investigación:

91. Aplicar las metodologías científicas más usuales en Psicología para la solución de problemas psicológicos.

Innovación y creatividad

92. Identificar problemas y mostrar interés por plantear una solución.

93. Generar ideas nuevas y ofrecer soluciones diferentes a los problemas profesionales.

94. Abordar un problema desde nuevas y diferentes perspectivas.

Crítica y autocrítica

95. Valorar la pertinencia aplicada de un resultado psicológico.

96. Utilizar habilidades de análisis sobre datos psicológicos.

98. Aplicar críticamente los principios de la Psicología al análisis de problemas sociales.

Investigación profesional

99. Delimitar el problema de investigación y buscar la información relevantes.

100. Establecer y refutar hipótesis de trabajo.

101.Interpretar resultados y generalizarlos relacionándolos con resultados previos. 


\section{Querer saber hacer:}

Actitudes y valores

102 Actitud de innovación y mejora profesional.

103. Actitud integradora del conocimiento teórico y el práctico. $-\frac{-}{-} \mathrm{AP}$

104. Valorar la importancia de la autocrítica personal. $\quad-\quad-\quad$ AP

105. Valorar la necesidad de realizar investigación en la práctica

profesional propia.

Normas

106. Ejercer un compromiso ético y respeto a los derechos de clientes

y usuarios.

\subsection{Competencias sociales de intervención profesional.}

Saber:

Hechos

107. Conocer otras culturas y costumbres de otros países.

108. Conocer la práctica profesional de otros países.

\section{Querer saber:}

Actitudes y valores

109. Mostrar interés por el conocimiento de otras culturas y costumbres de otros países.

110. Mostrar interés por el desarrollo de la profesión en otros países.

Normas

111.Compromiso ético en el manejo de información comparada sobre

la cultura y la profesión de otros países.

\section{Saber hacer:}

Habilidades interpersonales

112. Tener habilidades sociales.

113. Tener habilidades de negociación y persuasión.

114. Tener habilidades de comunicación.

PP

Liderazgo y trabajo en equipo

115. Dirigir y coordinar trabajos psicológicamente relevantes.

116. Conocer el manejo de los grupos desde una perspectiva psicol.

117. Realizar una dinámica de grupos.

118. Coordinar grupos de forma adecuada.

119. Aplicar técnicas de motivación e incentivación

120. Tener habilidades y estrategias de negociación y saber aplicarlas.

121. Dominar estrategias y técnicas psicológicas de resolución de problemas.

122. Conocer el contexto en que cada técnica tiene una eficacia diferencial mayor.

123. Asesorar a empresas, instituciones u organizaciones en el uso de modelos de intervención psicológica.

Adaptación a nuevas situaciones profesionales

124. Adaptación a situaciones nuevas en el ámbito laboral.

125. Mostrar capacidad para trabajar en un contexto internacional. $\begin{array}{lll}- & - & \mathrm{PP} \\ - & - & \mathrm{PP}\end{array}$

$\begin{array}{lll}- & - & \mathrm{PP} \\ - & - & \mathrm{PP}\end{array}$

PP

$-\quad P P$

- $-\mathrm{PP}$

$-\quad-\quad P P$

- PP

$\mathrm{PP}$
$\mathrm{PP}$

PP

PP

PP

PP

PP 


\section{Querer saber hacer:}

Actitudes y valores

126. Reconocer como importante la diversidad y la multiculturalidad.

127. Tener comprensión y aprecio de la diversidad cultural.

128. Respetar los derechos de clientes y usuarios.

Normas

129. Mostrar un compromiso ético y deontológico en el uso de las habilidades interpersonales.

130. Mostrar un compromiso ético y deontológico en situaciones de liderazgo trabajo en equipo e interdisciplinar. 